\title{
PREDICTION OF SOLID FAT CONTENT CURVE OF CHEMICALLY INTERESTERIFIED BLENDS OF PALM STEARIN AND SOYABEAN OIL
}

\author{
MOHAMMAD HOSSEIN NAELI*; JAMSHID FARMANI* and AZIZOLLAAH ZARGARAAN**
}

\begin{abstract}
Solid fat content (SFC) is a fundamental physico-chemical property of lipids. Common SFC determination methods are time-consuming and expensive. Here, regression models were used for description of the SFC of chemically interesterified palm stearin/soyabean oil blends as a function of fatty acid composition, temperature or both. Briefly, sigmoidal models described the SFC curves as a dependent variable of saturated fatty acids (SFA) very well $\left[S F C_{f(S F A)^{\prime}} R^{2}>0.98\right.$, mean absolute error $(M A E)<1.71 \%$ ] or temperature $\left[S F C_{f(T)^{\prime}}\right.$ $\left.R^{2}>0.98, M A E<1.67 \%\right]$. However, the Gompertz function predicted the $S F C_{f(S F A)}$ and $S F C_{f(T)}$ curves better than the other functions. Lastly, a Gompertz function describing SFC as a multiple function of both SFA and temperature $\left[S F C_{f(T, S A)}\right]$ was developed, which could describe the experimental data with $R^{2}=0.98$ and $M A E=1.86 \%$. Validation of the Gompertz $S F C_{f(S F A)}$ and $S F C_{f(T, S A)}$ models confirmed their high ability in prediction of SFC of different interesterified fats made from fully hydrogenated soyabean oil, palm stearin or palm olein.
\end{abstract}

Keywords: solid fat content, interesterified, palm stearin, temperature, fatty acid composition.

Date received: 14 January 2017; Sent for revision: 21 April 2017; Received in final form: 11 July 2018; Accepted: 9 October 2018.

\section{INTRODUCTION}

Solid fat content (SFC) is a measure of the ratio of fat in crystalline (solid) phase to total fat at a defined temperature. It is an important physical property, which directly affects fundamental characteristics such as spreadability, consistency and sensorial properties of fat products (Augusto et al., 2012; Dos Santos et al., 2013). SFC is generally measured across a temperature range $\left(10^{\circ} \mathrm{C}-40^{\circ} \mathrm{C}\right)$ to characterise the melting behaviour of fat. It is measured at

\footnotetext{
* Department of Food Science and Technology,

Faculty of Agricultural Engineering,

Sari Agricultural Sciences and Natural Resources University,

P.O. Box 578 , Sari, Iran.

E-mail: jamshid_farmani@yahoo.com

** Department of Food Science and Technology,

National Nutrition and Food Technology Research Institute,

Faculty of Nutrition Sciences and Food Technology, Shahid

Beheshti University of Medical Sciences,

P.O. Box 19395-4741, Tehran, Iran.
}

$10^{\circ} \mathrm{C}\left(50^{\circ} \mathrm{F}\right)$, as an indication of consistency during refrigeration, at $20^{\circ} \mathrm{C}$ (or $70^{\circ} \mathrm{F}$ ) to simulate room conditions during use, and at $35^{\circ} \mathrm{C}$ (or $92^{\circ} \mathrm{F}$ ) to approximate mouth feel or eating quality (Metzroth, 2005). The SFC profile is a good indicator of the plastic range of fats. Fats with the flattest SFC curves (such as all-purpose shortenings) have the widest plastic range for workability at cool temperatures as well as elevated temperatures. Narrow plastic range fats such as non-dairy and solid frying shortenings have relatively steep SFC curves, which will provide a firm, brittle consistency at room temperature but will be almost fluid at only slightly elevated temperatures (O'brien, 2008).

Pulsed nuclear magnetic resonance spectroscopy (pNMR) and differential scanning calorimetry (DSC) are the common SFC measurement methods (O'brien, 2008). However, these instruments are not available at all food analysis laboratories. Besides that, SFC determination methods are generally time-consuming. Accordingly, prediction of SFC 
curve of fats can be very useful in the design and development of new fat products and may eliminate the need for expensive instruments, as well (Dos Santos et al., 2014; Farmani et al., 2009). Augusto et al. (2012) tested the potential of some sigmoidal models in prediction of the SFC of interesterified, hydrogenated and/or fractionated fats. Dos Santos et al. $(2013$; 2014) computed the SFC curve of vegetable oils from their triacyglycerol (TAG) data using a solid-liquid equilibrium model. However, these models have disadvantages that limit their application. In fact, those presented by Augusto et al. (2012) do not consider the effect of fatty acids composition and that of Dos Santos et al. $(2013 ; 2014)$ need many data input for SFC prediction.

The most important factors that affect SFC are fat composition (TAG and fatty acid profile and other minor constituents), temperature at which the fat is held and polymorphic crystal forms (Farmani, 2015). In general, TAG profile is the most important factor determining fat melting, crystallisation and rheological properties. TAG melting properties are affected by fatty acid composition and their distribution within the glyceride molecule. The distribution of fatty acids among TAG of natural oils and fats is selective (1,3-random-2-random in vegetable oil and fats). This leads to the formation of different TAG compositions and consequently different physical properties, even at similar fatty acid compositions (Belitz et al., 2009). Interesterification re-distributes fatty acids among TAG of a fat without changing its fatty acid composition. Using chemical catalysts (such as sodium methoxide) or non-specific lipases, fatty acids are randomised among TAG, so that the TAG composition of the interesterified fat can be determined using the probability law. Accordingly, fats with similar fatty acid composition will have the same TAG composition after chemical interesterification, and consequently, similar physical properties (Belitz et al., 2009; Farmani, 2015). As an example, a blend composed of $50 \%$ tristearin (SSS) and 50\% triolein (OOO) has the same fatty acid composition of a blend composed of $50 \%$ oleodistearin (SSO) and 50\% stearodiolein (OOS). However, due to the difference in their TAG composition, the latter has a lower melting point than the former. After the chemical interesterification, both blends will have the same TAG profile and consequently the same physicochemical properties (Figure 1). Therefore, the effect of the TAG distribution pattern on melting properties of interesterified fats can be neglected. This means that the SFC curve of chemically interesterified fats can be correlated with their fatty acid composition. We used this strategy to describe the SFC curve of the chemically interesterified blends of fully hydrogenated soyabean/canola oils (Farmani, 2015) and chemically (Mahjoob et al., 2018) or enzymatically (Ebrahimi et al., 2017) interesterified blends of fully hydrogenated palm olein/soyabean oil as a function of saturated fatty acid (SFA, SFC $\left.f_{(S F A)}\right)$, temperature $\left(S_{f F C}\right)$, or both of them (SFC $\left.{ }_{f(S F A, T)}\right)$, elsewhere. As palm stearin is one of the main hard stocks used for the production of transfree fat products, this work aimed at studying the usefulness of the strategy further, by describing the SFC curve of interesterified blends of palm stearin $(10 \%-100 \%)$ and soyabean oil. Models presented in this work may be useful in SFC prediction and reduce costs of product formulation.

\section{MATERIALS AND METHODS}

\section{Materials}

Refined, bleached and deodourised palm stearin and soyabean oil were obtained from Noosh Azar Co. (Tehran, Iran). Sodium methoxide was purchased from Merck (Darmstadt, Germany). All other reagents (analytical grade) were obtained from Merck (Darmstadt, Germany).

\section{Chemical Interesterification}

Prior to the chemical interesterification, binary blends of palm stearin/soyabean oil in mass ratios of $10 / 90,20 / 80,30 / 70,40 / 60,50 / 50,60 / 40,70 / 30$,

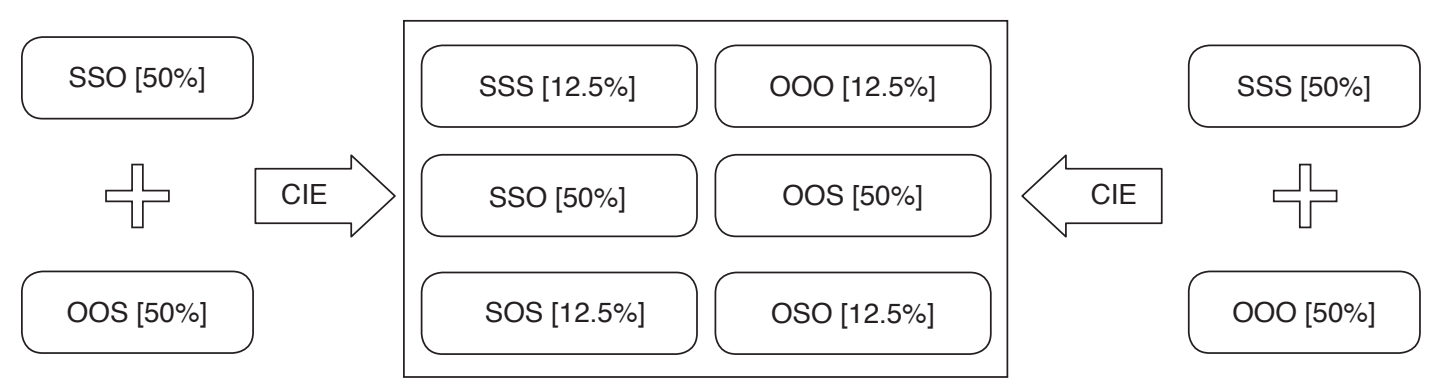

Figure 1. Schematic representation of chemical interesterification (CIE) of equal ratios of oleodistearin (SSO) and stearodiolein (OOS) blends or equal ratios of tristearin (SSS) and triolein (OOO) blends. The initial blends have different triacylglycerol (TAG) composition but have the same fatty acid composition (50\% stearic acid and 50\% oleic acid). After CIE that leads to the randomisation of TAG structure, both blends will have the same TAG profile. 
$80 / 20,90 / 10$ and 100/0 were prepared. Chemical interesterification was conducted using sodium methoxide $[0.5 \%(\mathrm{w} / \mathrm{w})]$, under vigorous magnetic stirring (300 rpm) for $1 \mathrm{hr}$ at $90^{\circ} \mathrm{C}$ and $0.8 \mathrm{bar}$ (abs.). The reaction was stopped by adding $2 \%(\mathrm{w} / \mathrm{w})$ aqueous citric acid solution $(20 \%, \mathrm{w} / \mathrm{v})$ and stirring using magnetic stirrer (300 rpm) at $70^{\circ} \mathrm{C}$ for $15 \mathrm{~min}$. Post-bleaching was performed by adding $1.5 \%$ bleaching earth (bentonite, Khak Rangbar Iran, Abhar) and stirring (300 rpm) for 15 min at 0.8 bar (abs.) and $110^{\circ} \mathrm{C}$. Finally, the mixture was vacuumfiltered through a Whatman No. 4 filter paper (Naeli et al., 2017).

\section{Fatty Acid Composition}

Fatty acid methyl esters (FAME) were prepared as described by the American Oil Chemists' Society (AOCS) method Ce 2-66 (AOCS, 1996). AOCS method Ce 1e-91 (AOCS, 1996) was followed to identify and quantify FAME by gas chromatography. An Agilent Acme 6100 gas chromatograph (Santa Clara, USA) equipped with the capillary chromatographic column CP Sil 88 (100 $\mathrm{m}, 0.25 \mathrm{~mm}$ id and $0.25 \mu \mathrm{m}$ film thickness) was used. Flame ionisation detector was used to detect the FAME. The GC was run isothermally at $198^{\circ} \mathrm{C}$, using a split ratio of $1: 40$ and setting the detector and injector at $280^{\circ} \mathrm{C}$ and $240^{\circ} \mathrm{C}$, respectively. Nitrogen was used as the carrier gas and the column head pressure was set at 29.5 PSI.

\section{Solid Fat Content}

SFC was determined at $10^{\circ} \mathrm{C}, 20^{\circ} \mathrm{C}, 30^{\circ} \mathrm{C}, 40^{\circ} \mathrm{C}$, $45^{\circ} \mathrm{C}$ and $50^{\circ} \mathrm{C}$ using a pulsed nuclear magnetic resonance spectroscope (Minispec mq 20, Bruker Corporation, Hamburg, Germany), as described in the AOCS Cd 16b-93 method (AOCS, 1996). Fat samples were melted at $100^{\circ} \mathrm{C}$ for $15 \mathrm{~min}$, held at $60^{\circ} \mathrm{C}$ for $15 \mathrm{~min}$ and transferred into the NMR tubes and then sample tubes were placed in an icebath $\left(0^{\circ} \mathrm{C}\right)$ for $60 \mathrm{~min}$. Before the measurement, the samples were conditioned for $35 \mathrm{~min}$ at the desired temperature $\left(10^{\circ} \mathrm{C}, 20^{\circ} \mathrm{C}, 30^{\circ} \mathrm{C}, 40^{\circ} \mathrm{C}, 45^{\circ} \mathrm{C}\right.$ and $\left.50^{\circ} \mathrm{C}\right)$.

\section{Modeling and Statistical Analyses}

In order to select the independent variables for modeling of the SFC, Pearson bivariate correlation coefficients between SFC, fatty acid composition and temperature were determined using SPSS for Windows (IBM SPSS Statistics Ver. 21, New York, USA). Based on the Pearson bivariate correlation results, model variables were selected and regression models were built for description of SFC of the interesterified palm stearin/soyabean oil blends as a function of fatty acid composition, temperature or both of them using SigmaPlot software Ver. 12 (Systat software Inc., USA) and SPSS Ver. 21 (New York, USA). In SFC modeling as a function of fatty acid composition, different models were described for each SFC measurement temperatures. For modeling SFC as a function of temperature, separate models were constructed for each blend. In SFC modeling as a multiple function of saturated fatty acid (SFA) and temperature, all the SFC, SFA and temperature data of all the blends were used for model construction. To evaluate the goodness of fit between experimental and predicted SFC values, the correlation coefficients between experimental and predicted values and mean absolute error (MAE) of prediction were calculated using STATISTICA Ver. 10 (Stat Soft Inc., Tulsa, USA) (Farmani, 2015). To validate the selected models, SFC curves of some chemically interesterified blends, whose SFC and fatty acid composition data were available from literature (Karabulut et al., 2004; Farmani et al., 2007; 2008; 2009; da Silva et al., 2010), were predicted and compared with the published experimental SFC curve. The prediction power of the models was evaluated by goodness of fit analysis, as described above.

\section{RESULTS AND DISCUSSION}

\section{Variable Selection}

Fatty acid composition and SFC of the interesterified palm stearin/soyabean oil blends are shown in Table 1. To select the independent variables, Pearson correlation coefficient between SFC and temperature, palmitic, stearic, oleic, linoleic, linolenic, unsaturated fatty acids (UFA) and SFA were determined (Table 2). Pearson correlation coefficients vary between -1 and +1 . A value of -1 shows a full negative and a value of +1 shows a full positive correlation (Bali, 1997). As expected, the variables palmitic, stearic and total SFA showed positive correlation with SFC, while oleic, linoleic, linolenic and total UFA and temperature had negative correlation with SFC (Table 2). All the correlations were significant $(p<0.01)$, which indicated their high potential to be used independent variables. Accordingly, the following strategies were used for SFC modeling: 1) SFC as a function of fatty acid composition, 2) SFC as a function of temperature, and 3) SFC as a function of temperature and SFA.

\section{Modeling of SFC as a Function of Fatty Acid Composition}

Palmitic, stearic, oleic, linoleic and linolenic acids were the main fatty acids found in the blends (totalling more than 97\%, Table 1). Therefore, it can be expected that the physico-chemical properties 
TABLE 1. FATTY ACID COMPOSITION AND SOLID FAT CONTENT OF CHEMICALLY INTERESTERIFIED BLENDS OF PALM STEARIN AND SOYABEAN OIL

\begin{tabular}{|c|c|c|c|c|c|c|c|c|c|c|c|c|c|c|}
\hline \multirow{2}{*}{ Blends } & \multicolumn{8}{|c|}{ Fatty acid composition $(\%)$} & \multicolumn{5}{|c|}{ SFC $(\%)$} & \multirow[b]{2}{*}{$50^{\circ} \mathrm{C}$} \\
\hline & 14:0 & $16: 0$ & 18:0 & 18:1 & $18: 2$ & $18: 3$ & SFA & UFA & $10^{\circ} \mathrm{C}$ & $20^{\circ} \mathrm{C}$ & $30^{\circ} \mathrm{C}$ & $40^{\circ} \mathrm{C}$ & $45^{\circ} \mathrm{C}$ & \\
\hline \multicolumn{15}{|l|}{$P S / S B O$} \\
\hline $10 / 90$ & 0.2 & 15.2 & 4.6 & 22.8 & 48.7 & 6.6 & 20.7 & 79.1 & 2.39 & 1.25 & 0.05 & 0 & 0 & 0 \\
\hline $20 / 80$ & 0.4 & 19.4 & 4.8 & 23.8 & 44.2 & 5.8 & 25.2 & 74.8 & 5.16 & 2.91 & 0.50 & 0 & 0 & 0 \\
\hline $30 / 70$ & 0.5 & 24.0 & 4.9 & 24.4 & 39.6 & 5.1 & 29.6 & 70.1 & 11.2 & 6.70 & 3.08 & 0.38 & 0 & 0 \\
\hline $40 / 60$ & 0.7 & 28.0 & 5.1 & 25.2 & 35.1 & 4.4 & 34.1 & 65.6 & 15.70 & 10.01 & 4.77 & 0.14 & 0 & 0 \\
\hline $50 / 50$ & 0.8 & 32.4 & 5.3 & 26.0 & 30.5 & 3.7 & 38.5 & 61.1 & 24.07 & 16.60 & 8.07 & 2.64 & 0.15 & 0 \\
\hline $60 / 40$ & 0.9 & 38.4 & 5.4 & 26.9 & 26.0 & 3.0 & 43.0 & 56.6 & 35.41 & 24.75 & 14.42 & 6.81 & 2.45 & 0 \\
\hline $70 / 30$ & 1.1 & 40.5 & 5.6 & 27.7 & 21.4 & 2.2 & 47.4 & 52.1 & 40.89 & 30.42 & 17.07 & 7.76 & 3.50 & 0.07 \\
\hline $80 / 20$ & 1.2 & 44.6 & 5.8 & 28.5 & 16.9 & 1.5 & 51.9 & 47.6 & 48.71 & 37.99 & 23.46 & 11.50 & 6.41 & 0.14 \\
\hline $90 / 10$ & 1.4 & 48.8 & 5.9 & 29.3 & 12.3 & 0.8 & 56.3 & 43.1 & 54.63 & 44.19 & 26.66 & 14.25 & 9.05 & 2.89 \\
\hline $100 / 0$ & 1.5 & 52.9 & 6.1 & 30.1 & 7.8 & 0.1 & 60.8 & 38.6 & 66.76 & 58.68 & 39.41 & 20.85 & 14.34 & 6.67 \\
\hline
\end{tabular}

Note: PS - palm stearin, SBO - soyabean oil, SFA - saturated fatty acids (sum of C14:0, C16:0 and C18:0), UFA - unsaturated fatty acid (sum of C18:1, C18:2 and C18:3). SFC - solid fat content.

TABLE 2. PEARSON CORRELATION COEFFICIENTS BETWEEN SOLID FAT CONTENT, TEMPERATURE AND FATTY ACID COMPOSITION OF CHEMICALLY INTERESTERIFIED PALM STEARIN AND SOYABEAN OIL BLENDS

\begin{tabular}{|c|c|c|c|c|c|c|c|c|c|}
\hline & SFC & $16: 0$ & 18:0 & $18: 1$ & $18: 2$ & $18: 3$ & SFA & UFA & $\mathbf{T}$ \\
\hline SFC & 1 & $0.961^{\mathrm{a}}$ & $0.964^{\mathrm{a}}$ & $-0.964^{\mathrm{a}}$ & $-0.964^{a}$ & $-0.964^{\mathrm{a}}$ & $0.964^{\mathrm{a}}$ & $-0.963^{a}$ & $-0.953^{a}$ \\
\hline $16: 0$ & $0.961^{\mathrm{a}}$ & 1 & $1.000^{\mathrm{a}}$ & $-0.999^{a}$ & $-1.000^{a}$ & $-1.000^{a}$ & $1.000^{\mathrm{a}}$ & $-1.000^{a}$ & - \\
\hline 18:0 & $0.964^{a}$ & $1.000^{\mathrm{a}}$ & 1 & $-1.000^{a}$ & $-1.000^{\mathrm{a}}$ & $-1.000^{a}$ & $1.000^{\mathrm{a}}$ & $-1.000^{a}$ & - \\
\hline $18: 1$ & $-0.964^{a}$ & $-0.999^{a}$ & $-1.000^{a}$ & 1 & $1.000^{\mathrm{a}}$ & $1.000^{\mathrm{a}}$ & $-1.000^{\mathrm{a}}$ & $1.000^{\mathrm{a}}$ & - \\
\hline $18: 2$ & $-0.964^{a}$ & $-1.000^{a}$ & $-1.000^{a}$ & $1.000^{\mathrm{a}}$ & 1 & $1.000^{\mathrm{a}}$ & $-1.000^{a}$ & $1.000^{\mathrm{a}}$ & - \\
\hline $18: 3$ & $-0.964^{a}$ & $-1.000^{a}$ & $-1.000^{a}$ & $1.000^{\mathrm{a}}$ & $1.000^{\mathrm{a}}$ & 1 & $-1.000^{a}$ & $1.000^{\mathrm{a}}$ & - \\
\hline SFA & $0.964^{\mathrm{a}}$ & $1.000^{\mathrm{a}}$ & $1.000^{\mathrm{a}}$ & $-1.000^{a}$ & $-1.000^{a}$ & $-1.000^{a}$ & 1 & $-1.000^{a}$ & - \\
\hline UFA & $-0.963^{a}$ & $-1.000^{a}$ & $-1.000^{a}$ & $1.000^{\mathrm{a}}$ & $1.000^{\mathrm{a}}$ & $1.000^{\mathrm{a}}$ & $-1.000^{a}$ & 1 & - \\
\hline $\mathrm{T}$ & $-0.953^{\mathrm{a}}$ & - & - & - & - & - & - & - & 1 \\
\hline
\end{tabular}

Note: SFA - saturated fatty acids (sum of C14:0, C16:0 and C18:0), UFA - unsaturated fatty acid (sum of C18:1, C18:2 and C18:3), $\mathrm{T}$ - temperature. SFC - solid fat content.

a Correlation coefficient was significant at the 0.01 level.

of the blends are extremely affected by the amount of these fatty acids. Multiple regression analysis is a good technique for studying the straight-line relationships among two or more variables. This technique estimates the coefficients between the response variable and several independent variables (Balan et al., 1995). The influence of fatty acids on SFC was evaluated using three different sets of equations: multiple effect of the individual fatty acids (Equation 1), multiple effect of SFA and UFA (Equation 2), and the effect of total SFA (Equations 3 to 6):

$$
\begin{array}{r}
\mathrm{SFC}_{f(P, S, O, L, L n)}=a(\mathrm{P})+b(\mathrm{~S})+c(\mathrm{O})+d(\mathrm{~L})+e(\mathrm{Ln})+f \\
\quad(\text { Equation } 1)
\end{array}
$$

where $a, b, c, d$, and $e$ are the regression coefficients and $f$ is the random error (or residual) which is the amount of variation in SFC not accounted for by the linear relationship; $P, S, O, L$ and $L n$ are palmitic, stearic, oleic, linoleic and linolenic acids content (the independent variables), respectively.

$$
\mathrm{SFC}_{f(S F A, U F A)}=a(\mathrm{SFA})+b(\mathrm{UFA})+f
$$

where $a$ and $b$ are the regression coefficients and $f$ is the random error.

To simplify the model and to take into account the simultaneous effect of palmitic and stearic acids (as the major SFA, Table 1), in the third strategy, total SFA was selected as the sole independent variable. Farmani (2015) pointed out that $\mathrm{SFC}_{f(S F A)}$ curve of interesterified fats is S-shaped and can be described using the sigmoidal functions. The sigmoidal functions describe S-shaped curves and are widely used in various areas (Augusto et al., 2012; Davenel et al., 1999). Accordingly, the $\mathrm{SFC}_{f(S F A)}$ curve of interesterified fats was modeled using four sigmoidal functions, i.e., the Sigmoid model 
(Equation 3), Gompertz model (Equation 4), Logistic model (Equation 5), and the Chapman model (Equation 6):

$$
\begin{aligned}
& S F C_{f(S F A)}=\frac{a}{1+e^{-\left(\frac{S F A-c}{b}\right)}} \\
& S F C_{f(S F A)}=a e^{-\mathrm{e}^{-\left(\frac{S F A-c}{b}\right)}} \\
& S F C_{f(S F A)}=\frac{a}{1+\left[\frac{S F A}{c}\right]^{b}} \\
& S F C_{f(S F A)}=a\left(1-e^{-b S F A}\right)^{c}
\end{aligned}
$$

(Equation 3)

(Equation 4)

(Equation 5)

(Equation 6)

where, $a$ is the upper asymptote, $b$ sets the ordinate axis displacement, $c$ sets the growth rate $(Y$ scaling) and $e$, Euler number $(e=2.71828)$.

Table 3 shows the obtained coefficients of the models describing SFC as a function of fatty acids composition (Equations 1 to 6) and their goodness of fit parameters. Generally, all the coefficients were significant at $\mathrm{p}<0.05$ and the models had $\mathrm{P}$ values less than 0.01 (result not shown). The $\mathrm{SFC}_{f(P, S, O, L, L n)}$ model suited SFC data somewhat better than the others did, especially at low solid contents (Table 3). However, it is important to mention that the multiple linear models estimated negative SFC values at low SFA (result not shown), and may not be suitable for describing the SFC at all the SFA range. Application of linear regressions for describing SFC of pork back fat as a function of fatty acid composition has been previously documented by Davenel et al. (1999), SFC at $20^{\circ} \mathrm{C}$ as a function of palmitic and stearic acids, $\mathrm{R}^{2}=0.94$; Gläser et al. (2004), with $\mathrm{SFC}$ at $20^{\circ} \mathrm{C}$ as a function of stearic acid, $\mathrm{R}^{2}=0.92$ and; Ospina-E et al. (2010), with SFC between $10^{\circ} \mathrm{C}$ and $40^{\circ} \mathrm{C}$, as a function of stearic acid.

In general, the sigmoidal models described the SFC data better than the multiple regression models (Table 3). All the sigmoidal models showed high values of $\mathrm{R}^{2}$ (0.981-0.999), as well as low levels of standard error (SE, less than 2.44) and MAE (less than $1.71 \%$ ). This indicates that the sigmoidal models can predict the SFC with low error. In fact, the $S_{F C}(S F A)$ curve of the interesterified blends of palm stearin / soyabean oil had an S-shape (Figure 2a). At low SFA content, the SFC tends to a minimum asymptotic value and with an increase of SFA content, the SFC values closes to maximum asymptotic value. The Gompertz and Chapman models described the experimental values slightly better than the other sigmoidal models (Table 3 ).

However, the Chapman model could not estimate SFC at $50^{\circ} \mathrm{C}\left(\mathrm{SFC}_{50}\right)$, therefore, the Gompertz model (Equation 4) was the most reliable option for modeling of SFC as a function of fatty acid composition. Similar to the present results, Farmani (2015) reported a high ability for Gompertz function in describing the of $S_{F C} C_{f(S F)}$ curve of interesterified blends of fully hydrogenated soyabean/canola oils
$\left(\mathrm{R}^{2}>0.97\right.$ and $\mathrm{MAE}<1.18 \%$.). Figure $2 a$ compares the SFC $_{f(S F A)}$ curves drawn from experimental data and those predicted from the Gompertz model (Equation 4). The correlation coefficient of experimental and predicted SFC ${ }_{f(S F A)}$ values were in the range of $0.991-$ 0.999 and MAE were lower than $1.19 \%$.

\section{Modeling of SFC as a Function of Temperature}

The $\mathrm{SFC}_{f(T)}$ curve of the interesterified blends of palm stearin/soyabean oil was described using sigmoidal functions, i.e., the Sigmoid model (Equation 7), Gompertz model (Equation 8), Logistic model (Equation 9), and the Hill model (Equation 10).

$$
\begin{aligned}
S F C_{f(T)} & =\frac{a}{1+e^{-\left(\frac{T-c}{b}\right)}} \\
S F C_{f(T)} & =a e^{-e-\left(\frac{T-c}{b}\right)} \\
S F C_{f(T)} & =\frac{a}{1+\left[\frac{T}{c}\right]^{b}} \\
S F C_{f(T)} & =\frac{a T^{b}}{C^{b}+T^{b}}
\end{aligned}
$$

where, $a$ is the upper asymptote, $b$ sets the ordinate axis displacement, $c$ sets the growth rate $(Y$ scaling) and $e$, Euler number $(e=2.71828)$.

The coefficients of the proposed models for prediction of the $\mathrm{SFC}_{f(T)}$ curve of the interesterified blends of palm stearin/soyabean oil, and their goodness of fit parameters are presented in Table 4. Generally, all the coefficients were significant at $p<0.05$ (result not shown). As it can be seen, all models had high $R^{2}(>0.984)$ and were significant at $\mathrm{p}<0.001$. The $\mathrm{SFC}_{f(T)}$ curves could be described using the sigmoidal models with MAE and SE lower than $1.67 \%$ and $2.97 \%$, respectively, which indicated the low prediction error of the models. However, the Gompertz $\mathrm{SFC}_{f(T)}$ model (Equation 8) described it better especially at lower SFC values (the $\mathrm{R}^{2}$, MAE and correlation coefficient of experimental and predicted $\mathrm{SFC}_{f(T)}$ values were in the range of $0.996 \%-1.000 \%, 0.00 \%-1.01 \%$ and $0.998 \%-1.000 \%$, respectively). The experimental and predicted $S_{\text {FC }}$ curve of interesterified palm stearin/soyabean oil blends are compared in Figure $2 b$. As illustrated in Figure $2 b$, the $\mathrm{SFC}_{f(T)}$ curve of interesterified fats was also S-shaped. The effect of temperature on the SFC of the blends can be divided into three distinct phases: an initial and a final slow decrease and an intermediate rapid decrease. The first phase may represent the temperature range at which the fat contains high solid content and the SFC tends to a maximum asymptotic value. At intermediate temperature range, the SFC decays with an inflexion point. Finally, with increase of temperature to the fat melting point, when the fat melts completely, the SFC tends to a minimum asymptotic value of $0 \%$.

Augusto et al. (2012) set up the Gompertz, power decay and Logistic models to express the 
TABLE 3. COEFFICIENTS OF THE MULTIPLE LINEAR AND SIGMOIDAL MODELS (equations 1 to 6) DESCRIBING SOLID FAT CONTENT AS A FUNCTION OF FATTY ACID COMPOSITION AND GOODNESS OF FIT OF MODELS

\begin{tabular}{|c|c|c|c|c|c|c|c|c|c|c|}
\hline \multirow[t]{2}{*}{ Models } & \multicolumn{6}{|c|}{ Coefficients of models } & \multicolumn{4}{|c|}{ Goodness of fit } \\
\hline & $a$ & $b$ & $c$ & $d$ & $e$ & $f$ & $\mathbf{r}$ & $\mathbf{R}^{2}$ & $\mathrm{SE}$ & MAE \\
\hline \multicolumn{11}{|c|}{$\begin{array}{l}\text { Multiple Linear SFC } \\
\text { (Eq }(P, S, O, L, L n) \\
\text { (E) }\end{array}$} \\
\hline $\mathrm{SFC}_{10}$ & -14.330 & 823.391 & -26.320 & 494.902 & 3201 & 0.008 & 0.998 & 0.997 & 1.21 & 1.54 \\
\hline $\mathrm{SFC}_{20}$ & -20.600 & 1291 & -31.525 & -839.149 & 5451 & 0 & 0.996 & 0.999 & 1.84 & 1.85 \\
\hline $\mathrm{SFC}_{30}$ & -16.964 & 1267 & -28.649 & -869.752 & 5665 & 0.010 & 0.991 & 0.982 & 1.79 & 2.19 \\
\hline $\mathrm{SFC}_{40}$ & -13.08 & 931.871 & -18.825 & -639.737 & 4165 & 0.074 & 0.993 & 0.987 & 0.98 & 1.37 \\
\hline $\mathrm{SFC}_{45}$ & -11.328 & 819.218 & -15.100 & -570.637 & 3717 & 0 & 0.975 & 0.953 & 1.27 & 1.35 \\
\hline $\mathrm{SFC}_{50}$ & -4.762 & 622.324 & -9.092 & -473.978 & 3106 & 0.018 & 0.856 & 0.733 & 1.05 & 0.83 \\
\hline \multicolumn{11}{|c|}{$\begin{array}{l}\text { Multiple Linear SFC }{ }_{f(U F A, S F A)} \\
\text { (Eq. 2) }\end{array}$} \\
\hline $\mathrm{SFC}_{10}$ & 1.268 & -0.360 & - & - & - & 0.015 & 0.993 & 0.986 & 2.75 & 1.92 \\
\hline $\mathrm{SFC}_{20}$ & 11.821 & 10.298 & - & - & - & -1066 & 0.980 & 0.959 & 3.96 & 2.65 \\
\hline $\mathrm{SFC}_{30}$ & 9.614 & 8.584 & - & - & - & -884.522 & 0.964 & 0.930 & 3.51 & 2.44 \\
\hline $\mathrm{SFC}_{40}$ & 9.984 & 9.370 & - & - & - & -953.210 & 0.943 & 0.889 & 2.40 & 1.67 \\
\hline $\mathrm{SFC}_{45}$ & 10.059 & 9.623 & - & - & - & -974.073 & 0.890 & 0.790 & 2.18 & 1.66 \\
\hline $\mathrm{SFC}_{50}$ & 5.018 & 4.851 & - & - & - & -489.691 & 0.690 & 0.480 & 1.15 & 1.10 \\
\hline \multicolumn{11}{|c|}{$\begin{array}{l}\text { Sigmoid } \mathrm{SFC}_{f(S F A)} \\
(\text { Eq. 3) }\end{array}$} \\
\hline $\mathrm{SFC}_{10}$ & 75.5896 & 8.9704 & 45.7543 & - & - & - & 0.995 & 0.990 & 2.44 & 1.71 \\
\hline $\mathrm{SFC}_{20}$ & 82.4793 & 9.9589 & 53.1768 & - & - & - & 0.994 & 0.986 & 2.23 & 1.53 \\
\hline $\mathrm{SFC}_{30}$ & 70.4614 & 10.1383 & 59.3701 & - & - & - & 0.990 & 0.981 & 2.02 & 1.33 \\
\hline $\mathrm{SFC}_{40}$ & 32.6128 & 7.9578 & 56.9916 & - & - & - & 0.992 & 0.978 & 1.20 & 0.79 \\
\hline $\mathrm{SFC}_{45}$ & 26.6714 & 6.4884 & 60.0473 & - & - & - & 0.994 & 0.989 & 0.57 & 0.39 \\
\hline $\mathrm{SFC}_{50}$ & 6.9663 & 1.2820 & 56.8281 & - & - & - & 0.999 & 0.999 & 0.02 & 0.00 \\
\hline \multicolumn{11}{|c|}{$\begin{array}{l}\text { Gompertz SFC }_{f(S F A)} \\
(\text { Eq. 4) }\end{array}$} \\
\hline $\mathrm{SFC}_{10}$ & 101.8904 & 19.4300 & 45.5768 & - & - & - & 0.997 & 0.994 & 1.84 & 1.19 \\
\hline $\mathrm{SFC}_{20}$ & 154.0154 & 27.2105 & 60.8501 & - & - & - & 0.996 & 0.993 & 1.76 & 1.08 \\
\hline $\mathrm{SFC}_{30}$ & 185.5104 & 33.0948 & 76.2727 & - & - & - & 0.992 & 0.985 & 1.76 & 1.04 \\
\hline $\mathrm{SFC}_{40}$ & 65.7834 & 22.8790 & 64.7158 & - & - & - & 0.991 & 0.983 & 1.04 & 0.06 \\
\hline $\mathrm{SFC}_{45}$ & 88.4058 & 23.5440 & 75.1207 & - & - & - & 0.996 & 0.992 & 0.48 & 0.30 \\
\hline $\mathrm{SFC}_{50}$ & 9.2383 & 3.4971 & 56.9124 & - & - & - & 0.999 & 0.999 & 0.02 & 0.00 \\
\hline \multicolumn{11}{|c|}{$\begin{array}{l}\text { Logistic SFC }_{f(S F A)} \\
(\text { Eq. } 5)\end{array}$} \\
\hline $\mathrm{SFC}_{10}$ & 103.9962 & -3.7040 & 53.2532 & - & - & - & 0.997 & 0.994 & 1.89 & 1.23 \\
\hline $\mathrm{SFC}_{20}$ & 172.7376 & -3.4464 & 74.7954 & - & - & - & 0.996 & 0.993 & 1.76 & 1.11 \\
\hline $\mathrm{SFC}_{30}$ & 378.0900 & -3.5272 & 113.2348 & - & - & - & 0.993 & 0.986 & 1.73 & 1.12 \\
\hline $\mathrm{SFC}_{40}$ & 58.1426 & -5.0397 & 68.8806 & - & - & - & 0.991 & 0.982 & 1.07 & 0.67 \\
\hline $\mathrm{SFC}_{45}$ & 48.0986 & -6.8082 & 69.1566 & - & - & - & 0.995 & 0.991 & 0.51 & 0.32 \\
\hline $\mathrm{SFC}_{50}$ & 7.0646 & -42.1900 & 56.8802 & - & - & - & 0.999 & 0.999 & 0.02 & 0.00 \\
\hline \multicolumn{11}{|c|}{$\begin{array}{l}\text { Chapman } \mathrm{SFC}_{f(S F A)} \\
\text { (Eq. 6) }\end{array}$} \\
\hline $\mathrm{SFC}_{10}$ & 113.5933 & 0.0422 & 7.0367 & - & - & - & 0.997 & 0.995 & 1.78 & 1.12 \\
\hline $\mathrm{SFC}_{20}$ & 244.8387 & 0.0227 & 5.0628 & - & - & - & 0.997 & 0.994 & 1.68 & 1.00 \\
\hline $\mathrm{SFC}_{30}$ & 613.8279 & 0.0132 & 4.6816 & - & - & - & 0.993 & 0.986 & 1.70 & 1.02 \\
\hline $\mathrm{SFC}_{40}$ & 85.3203 & 0.0345 & 11.0291 & - & - & - & 0.992 & 0.984 & 1.02 & 0.06 \\
\hline $\mathrm{SFC}_{45}$ & 0.8516 & 0.0346 & 16.4283 & - & - & - & 0.996 & 0.999 & 0.48 & 0.29 \\
\hline $\mathrm{SFC}_{50}$ & - & - & - & - & - & - & - & - & - & - \\
\hline
\end{tabular}

Note: SFA - saturated fatty acids (sum of C14:0, C16:0 and C18:0), UFA - unsaturated fatty acid (sum of C18:1, C18:2 and C18:3), $\mathrm{r}$ - correlation coefficient between experimental and predicted values, $\mathrm{R}^{2}$ - coefficient of determination, $\mathrm{SE}$ - standard error, MAE - mean absolute error. SFC - solid fat content. 
(a)

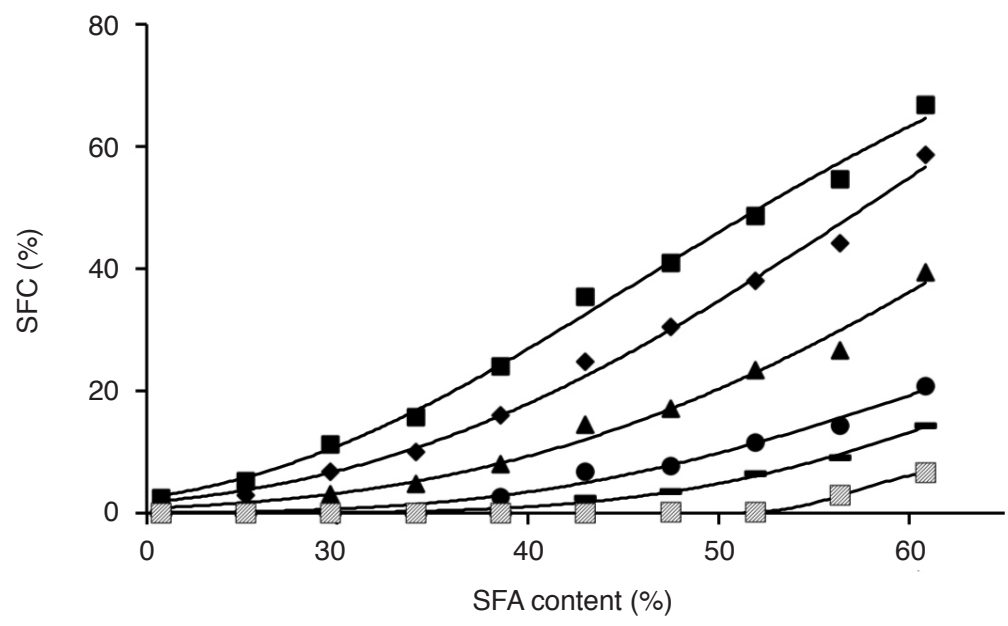

- SFC10

- SFC20

$\Delta$ SFC30

- SFC40

- SFC45

曾 SFC50

(b)

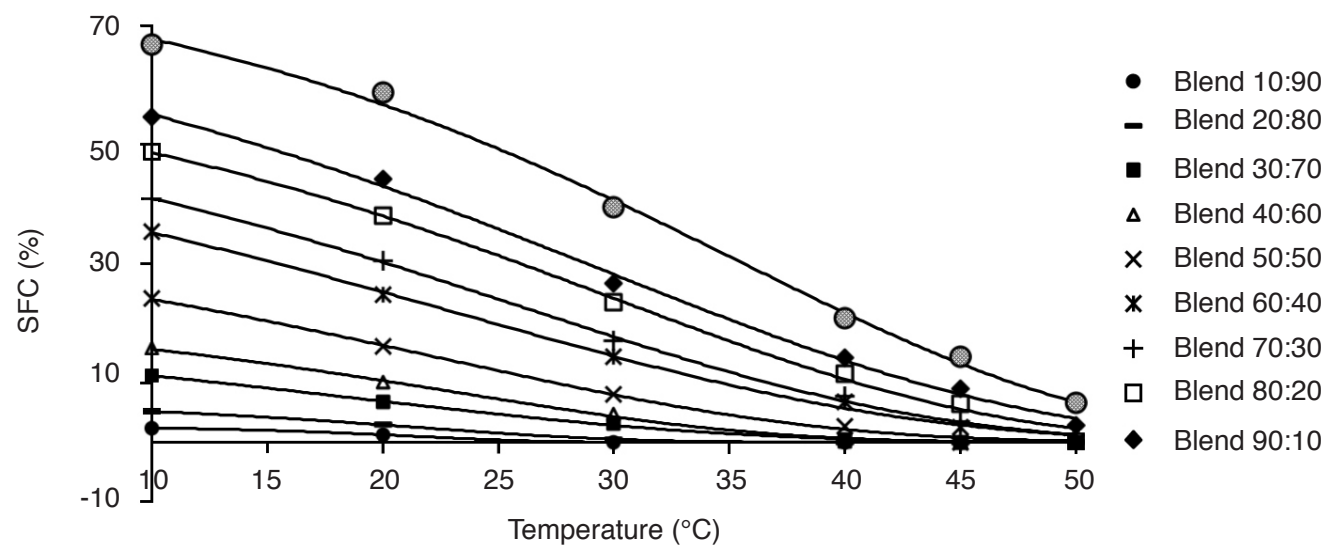

(c)

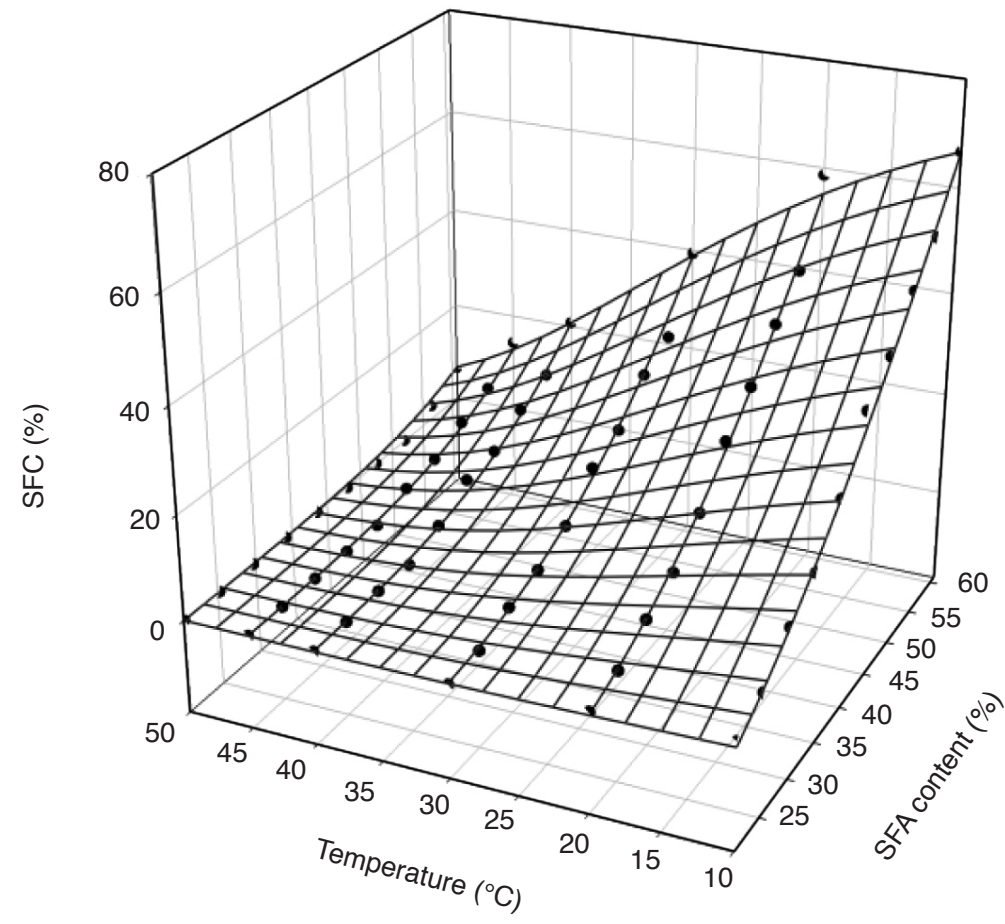

Figure 2. Effect of saturated fatty acids content (a), temperature (b) or both of them (c) on solid fat content (SFC) of interesterified palm stearin and soyabean oil blends. Markers are the experimental values; solid lines represent predicted SFC curves by the Gompertz model (Equations 4, 8 and 11). 
$\mathrm{SFC}_{f(T)}$ curves of chemically interesterified blends of fully hydrogenated soyabean oil/canola oil. They reported that the models described the experimental data well $\left(R^{2}>0.96\right)$, however, the Gompertz model was the strongest, especially at low and high values of solid content. Farmani (2015) also documented the suitability of Gompertz model for modeling the effects of temperature on SFC of interesterified fully hydrogenated soyabean/canola oils blends $\left(\mathrm{R}^{2}>\right.$ 0.95 and $\mathrm{MAE}<1.61 \%$ ).

\section{Modeling of SFC as a Function of Temperature and SFA}

None of the proposed models (Equations 1 to 10) expresses the simultaneous influence of temperature and SFA on SFC. We have suggested a two-variable model for expression of SFC as a function of both temperature and SFA content by some substitutions in Gompertz function, elsewhere (Farmani, 2015). For this purpose, we expressed the coefficients $a$ and $c$ of the Gompertz SFC ${ }_{f(T)}$ model as linear functions of SFA. Then by replacing coefficients $a$ and $c$ of Gompertz SFC $_{f(T)}$ with the linear functions of SFA, the two-variable Gompertz $S_{f F C}(T, S F A)$ model was described as bellow:

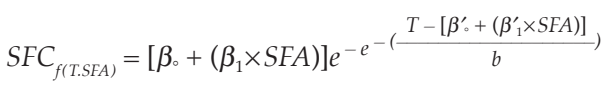

(Equation 11)

The SFC data of the interesterified palm stearin/ soyabean oil blends (over $10^{\circ} \mathrm{C}-50^{\circ} \mathrm{C}$ ) were fitted to the function and coefficients of the equation were calculated (Equation 12):

$S F C_{f(T . S F A)}=[-33.0563+(2.4564 \times S F A)] e^{-e^{-\left(\frac{T-[-6.9735+(0.5587 \times S F A)]}{-22.2457}\right)}}$

(Equation 12)

Generally, all the coefficients were significant at $\mathrm{p}<0.05$ and the model had a $P$ value less than 0.0001. Experimental and predicted SFC values are compared in Figure 2c. The $\mathrm{R}^{2}, \mathrm{SE}, \mathrm{MAE}$ and correlation coefficient of the model were $0.982 \%$, $1.32 \%, 1.86 \%$ and $0.991 \%$ respectively, which indicated the high prediction power of the model. Application of a two-variable quadratic equation for modeling of SFC of pork back fat as a function of temperature and stearic acid content has been previously documented by Ospina-E et al. (2010). However, it is important to note that quadratic models are not suitable for modeling of S-shaped curves such as the SFC curve (Augusto et al., 2012).

\section{Validation of Models}

To validate the Gompertz $\mathrm{SFC}_{f(S F A)}$ and $\mathrm{SFC}_{f(T, S F A)}$ models (Equations 4 and 12), their ability in prediction of the SFC curve of several chemically interesterified blends including binary blends of fully hydrogenated soyabean oil/canola oil, palm olein/ canola oil (Farmani et al., 2009), palm stearin/ olive oil (da Silva et al., 2010), palm stearin/canola oil (Karabulut et al., 2004) and ternary blends of fully hydrogenated soyabean oil/canola oil/sunflower oil (Farmani et al., 2007) and palm olein/canola oil/ sunflower oil (Farmani et al., 2008) were investigated (Table 5).

Table 5 shows the experimental and predicted SFC of different interesterified fat blends by the Gompertz $S_{f F C}$ and $S F C_{f(T, S F A)}$ models (Equations 4 and 12). The Gompertz SFC f(SFA) model could predict the SFC of various types of binary or ternary interesterified blends with MAE less than $2.75 \%$ (Table 5). The model could predict the SFC of interesterified palm stearin/canola oil and palm stearin/olive oil blends with $2.17 \%$ and $2.48 \%$ MAE, respectively. For binary or ternary interesterified blends composed of palm olein, MAE was $1.79 \%$ and $1.94 \%$, respectively. The correlation coefficient between experimental and predicted values was also high for binary (0.96) and ternary (0.98) palm olein-based blends. For the interesterified binary or ternary fully hydrogenated soyabean oil-based blends, MAE of the model was $1.5 \%$ and $2.75 \%$, respectively. High correlation coefficients were found between experimental and predicted SFC of the interesterified binary (0.99) or ternary (0.98) fully hydrogenated soyabean oil-based blends.

MAE of the Gompertz SFC ${ }_{f(T, S F A)}$ model was $0.96 \%$ and $2.21 \%$, respectively, and correlation coefficient was 0.99 and 0.97 , respectively, for binary or ternary interesterified blends composed of fully hydrogenated soyabean oil (Table 5). The model also showed a high ability to estimate the SFC of the interesterified binary or ternary palm olein-based blends (with $1.29 \%$ and $1.55 \%$ MAE, respectively). High correlation coefficient (0.99) was also found between experimental and predicted values. For interesterified blends of palm stearin/canola oil and palm stearin/olive oil, the MAE was $2.00 \%$ and $1.80 \%$, respectively, and the correlation coefficient was 0.99 and 0.98 , respectively.

Both the Gompertz $S_{f(S F A)}$ and $S_{f F C}(T, S F A)$ models (Equations 4 and 12) predicted well the SFC of different interesterified fats. However, the Gompertz $\mathrm{SFC}_{f(T, S F A)}$ model estimated it slightly better.

The Gompertz $S_{F C} C_{f(T, S F)}$ model proposed by Farmani (2015) was able to predict the SFC of binary blends of palm olein/ canola oil, palm olein/ canola oil/sunflower oil and ternary blends of fully hydrogenated soyabean oil/canola oil/sunflower oil with MAE 1.0\%-3.5\%. For binary or ternary interesterified blends composed of palm olein, the MAE of that model was higher than that obtained from this study $(3.5 \%-2.60 \%$ vs. $1.2 \%-1.55 \%)$. The 
TABLE 4. COEFFICIENTS OF THE SIGMOIDAL MODELS (equations 7 to 10) DESCRIBING SOLID FAT CONTENT AS A FUNCTION OF TEMPERATURE AND GOODNESS OF FIT OF MODELS

\begin{tabular}{|c|c|c|c|c|c|c|c|c|c|}
\hline \multirow{2}{*}{ Models } & \multirow{2}{*}{$P S / S B O$} & \multicolumn{3}{|c|}{ Coefficients of models } & \multicolumn{5}{|c|}{ Goodness of fit } \\
\hline & & a & $\mathbf{b}$ & c & $\mathbf{r}$ & $\mathbf{R}^{2}$ & $\mathbf{P}$ & SE & MAE \\
\hline \multirow{10}{*}{$\begin{array}{c}\text { Sigmoid SFC }_{f(T)} \\
\text { (Eq. 7) }\end{array}$} & $10 / 90$ & 2.4501 & -3.0599 & 19.9395 & 0.998 & 0.997 & $0.0001>$ & 0.06 & 0.03 \\
\hline & $20 / 80$ & 5.5860 & -4.1321 & 20.3529 & 0.999 & 0.999 & $0.0001>$ & 0.02 & 0.01 \\
\hline & $30 / 70$ & 13.7808 & -6.8901 & 20.0312 & 0.997 & 0.994 & 0.0004 & 0.41 & 0.26 \\
\hline & $40 / 60$ & 14.8820 & -6.3145 & 22.0762 & 0.995 & 0.991 & 0.0008 & 0.77 & 0.47 \\
\hline & $50 / 50$ & 28.0754 & -7.2054 & 22.5936 & 0.997 & 0.991 & 0.0004 & 0.93 & 0.56 \\
\hline & $60 / 40$ & 42.2802 & -8.6223 & 23.6874 & 0.996 & 0.992 & 0.0007 & 1.55 & 0.97 \\
\hline & $70 / 30$ & 46.6477 & -8.0468 & 25.4375 & 0.997 & 0.995 & 0.0003 & 1.40 & 0.73 \\
\hline & $80 / 20$ & 53.8651 & -8.2362 & 27.8732 & 0.996 & 0.992 & 0.0007 & 2.16 & 1.10 \\
\hline & $90 / 10$ & 62.2727 & -9.0614 & 27.8897 & 0.998 & 0.996 & 0.0002 & 1.60 & 0.91 \\
\hline & $100 / 0$ & 72.3143 & -8.6307 & 32.0018 & 0.999 & 0.998 & $0.0001>$ & 1.27 & 0.81 \\
\hline \multirow{10}{*}{$\begin{array}{c}\text { Gompertz SFC }_{f(T)} \\
\text { (Eq. 8) }\end{array}$} & $10 / 90$ & 2.6876 & -5.3319 & 21.4152 & 1.000 & 0.999 & $0.0001>$ & 0.01 & 0.00 \\
\hline & $20 / 80$ & 6.8305 & -8.9601 & 21.4222 & 1.000 & 1.000 & $0.0001>$ & 0.00 & 0.00 \\
\hline & $30 / 70$ & 20.3070 & -16.7492 & 18.6444 & 0.999 & 0.998 & $0.0001>$ & 0.22 & 0.14 \\
\hline & $40 / 60$ & 22.4064 & -13.2029 & 23.3930 & 0.998 & 0.997 & 0.0002 & 0.45 & 0.26 \\
\hline & $50 / 50$ & 38.3445 & -16.5229 & 22.5259 & 0.999 & 0.998 & $0.0001>$ & 0.59 & 0.30 \\
\hline & $60 / 40$ & 58.0787 & -19.5426 & 23.5154 & 0.998 & 0.996 & 0.0002 & 1.02 & 0.56 \\
\hline & $70 / 30$ & 60.7789 & -17.5759 & 26.2919 & 0.999 & 0.997 & 0.0001 & 0.95 & 0.51 \\
\hline & $80 / 20$ & 65.4202 & -16.5163 & 30.0515 & 0.998 & 0.996 & 0.0002 & 1.51 & 0.80 \\
\hline & $90 / 10$ & 78.0034 & -18.6651 & 29.6542 & 0.998 & 0.996 & 0.0002 & 1.47 & 0.96 \\
\hline & $100 / 0$ & 82.8356 & -15.8507 & 35.3588 & 0.998 & 0.997 & 0.0001 & 1.66 & 1.01 \\
\hline \multirow{10}{*}{$\begin{array}{c}\text { Logistic SFC }_{f(T)} \\
\text { (Eq. 9) }\end{array}$} & $10 / 90$ & 2.3422 & 7.1757 & 20.0890 & 0.997 & 0.994 & $0.0001>$ & 0.09 & 0.06 \\
\hline & $20 / 80$ & 5.2159 & 6.2983 & 20.7677 & 0.999 & 0.999 & $0.0001>$ & 0.05 & 0.03 \\
\hline & $30 / 70$ & 11.5369 & 4.3163 & 22.0018 & 0.994 & 0.984 & 0.001 & 0.59 & 0.37 \\
\hline & $40 / 60$ & 15.8932 & 4.6206 & 23.0277 & 0.992 & 0.985 & 0.0018 & 1.03 & 0.64 \\
\hline & $50 / 50$ & 24.3980 & 4.2803 & 24.0103 & 0.994 & 0.988 & 0.0012 & 1.37 & 0.82 \\
\hline & $60 / 40$ & 35.8348 & 3.8543 & 25.7642 & 0.992 & 0.984 & 0.0018 & 2.19 & 1.41 \\
\hline & $70 / 30$ & 41.0288 & 4.1446 & 26.8050 & 0.994 & 0.989 & 0.001 & 2.10 & 1.30 \\
\hline & $80 / 20$ & 48.3107 & 4.2123 & 28.8518 & 0.992 & 0.985 & 0.0018 & 2.97 & 1.67 \\
\hline & $90 / 10$ & 54.9120 & 3.9511 & 29.4064 & 0.996 & 0.993 & 0.0005 & 2.15 & 1.15 \\
\hline & $100 / 0$ & 66.5658 & 4.3129 & 23.7180 & 0.998 & 0.996 & 0.0002 & 1.78 & 0.99 \\
\hline \multirow{10}{*}{$\begin{array}{l}\text { Hill SFC }_{f(T)} \\
\text { (Eq. 10) }\end{array}$} & $10 / 90$ & 2.3422 & -7.1758 & 20.089 & 0.997 & 0.994 & $0.0001>$ & 0.99 & 0.06 \\
\hline & $20 / 80$ & 5.2153 & -6.2983 & 20.7677 & 0.999 & 0.999 & $0.0001>$ & 0.05 & 0.03 \\
\hline & $30 / 70$ & 11.5369 & -4.3163 & -4.0018 & 0.994 & 0.989 & 0.001 & 0.59 & 0.37 \\
\hline & $40 / 60$ & 15.8932 & -4.6205 & 23.0277 & 0.992 & 0.985 & 0.0018 & 1.03 & 0.64 \\
\hline & $50 / 50$ & 24.3980 & -4.2802 & 24.0103 & 0.994 & 0.988 & 0.0012 & 1.37 & 0.82 \\
\hline & $60 / 40$ & 35.8348 & -3.8543 & 25.7642 & 0.992 & 0.984 & 0.0018 & 2.19 & 1.41 \\
\hline & $70 / 30$ & 41.0287 & -4.1446 & 26.8050 & 0.994 & 0.989 & 0.001 & 2.10 & 1.30 \\
\hline & $80 / 20$ & 48.3107 & -4.2132 & 28.8598 & 0.992 & 0.985 & 0.001 & 2.97 & 1.67 \\
\hline & $90 / 10$ & 54.9140 & 3.9511 & 29.4064 & 0.996 & 0.993 & 0.0005 & 2.15 & 1.15 \\
\hline & $100 / 0$ & 66.5958 & -4.3129 & 32.7180 & 0.998 & 0.996 & 0.0002 & 1.78 & 0.99 \\
\hline
\end{tabular}

Note: T - temperature, PS - palm stearin, SBO - soyabean oil, $\mathrm{r}$ - correlation coefficient between experimental and predicted values, $\mathrm{R}^{2}$-coefficient of determination, $\mathrm{P}$ - probability level of model, SE - standard error, MAE - mean absolute error. SFC - solid fat content.

MAE for fully hydrogenated soyabean oil/canola oil blends obtained in our study was close to the results of Farmani (2015) (0.96\% vs. 1.00\%). This may be due to the similarity of fatty acid composition of interesterified binary or ternary palm olein-based blends to blends that were used to fit the model (palm stearin/soyabean oil). Palmitic acid was the main SFA of palm stearin/soyabean oil, palm olein/ canola oil and palm olein/canola oil/sunflower oil blends, while the major SFA of fully hydrogenated soyabean oil/canola oil blends was stearic acid, which has a different melting point from palmitic acid (Tables 1 and 2). The MAE of SFC prediction for fully hydrogenated soyabean oil/canola oil blends in our study was close to the results of Farmani (2015) (0.96\% vs. 1.00\%). Dos Santos et al. (2013; 2014) presented a solid-liquid equilibrium model for modeling of the melting curves of chemically interesterified fats including binary blends of fully hydrogenated palm stearin/canola oil, palm 


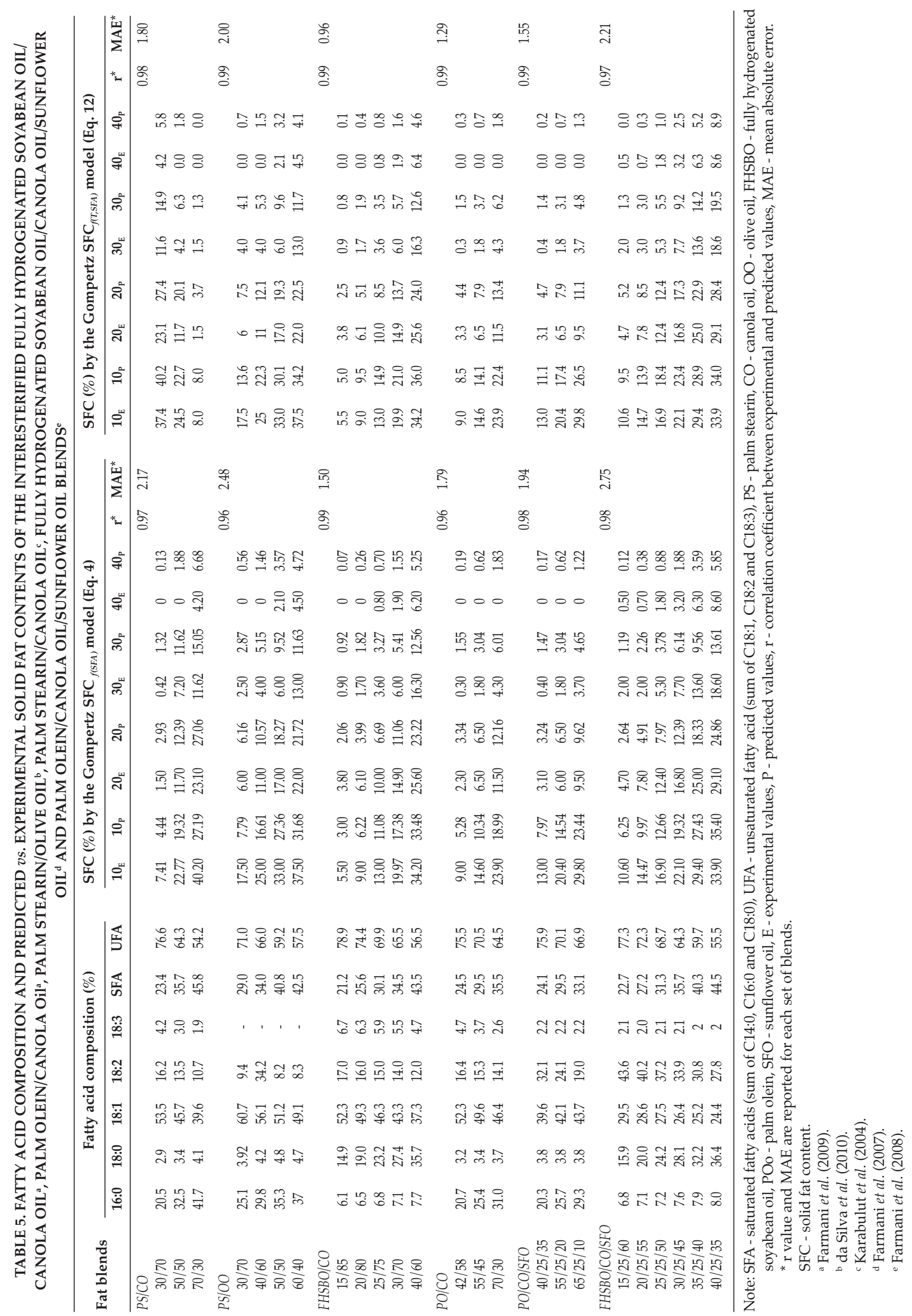


stearin/canola oil, palm stearin/cottonseed oil, milk fat/corn oil and ternary blends of palm oil/ sunflower oil/palm kernel olein. They reported a MAE of $4.13 \%$ and a MAE of $4.2 \%$ for binary and ternary blends, respectively.

\section{CONCLUSION}

The findings of this research provide insights for the mathematical properties of melting profile of interesterified fats. In summary, all the proposed models showed good ability in predicting the SFC of interesterified soyabean oil and palm stearin blends. However, the Gompertz model was the strongest and most reliable option for this purpose. Results of model validation showed that the Gompertz SFC ${ }_{f(S F A)}$ and SFC ${ }_{f(T, S F A)}$ models can predict the SFC curves of chemically interesterified fully hydrogenated soyabean oil/canola oil, palm olein/canola oil, palm stearin/olive oil, palm stearin/canola oil, fully hydrogenated soyabean oil/canola oil/sunflower oil and palm olein/ canola oil/sunflower oil blends, in the best way. Results of this study may be useful in screening of a large volume of blends in design and development of new interesterified fat formulations.

\section{REFERENCES}

AOCS (1996). Official Methods and Recommended Practices of the American Oil Chemists' Society. $4^{\text {th }}$ Ed., AOCS Press, Champaign.

AUGUSTO, P E D; SOARES, B M C; CHIU, M C and GONCALVES, L A G (2012). Modelling the effect of temperature on the lipid solid fat content (SFC). Food Res. Int., 45(1): 132-135. DOI: 10.1016/j. foodres.2011.10.026.

BALAN, B; MOHAGHEGH, $S$ and AMERI, S (1995). State-of-the-art in Permeability Determination from Well Log Data. Part 1 - A Comparative Study, Model Development. SPE Eastern Regional Meeting. Society of Petroleum Engineers. Morgantown, 18-20 September 1995.

BALI, N P (1997). Comprehensive Engineering Mathematics. Laxmi Publications, New Dehli.

BELITZ, H D; GROSCH, W and SCHIEBERLE, P (2009). Food Chemistry. Springer, Berlin.

DA SILVA, R C; SOARES, D F; LOURENCO, M B; SOARES, F A; DA SILVA, K G; GONCALVES, M I A and GIOIELLI, LA (2010). Structured lipids obtained by chemical interesterification of olive oil and palm stearin. LWT- Food Sci. Technol., 43(5): 752-758. DOI: 10.1016/j.lwt.2009.12.010.
DAVENEL, A; RIAUBLANC, A; MARCHAL, P and GANDEMER, G (1999). Quality of pig adipose tissue: Relationship between solid fat content and lipid composition. Meat Sci., 51(1): 73-79. DOI: 10.1016/S0309-1740(98)00099-0.

DOS SANTOS, M T; GERBAUD, V L E and ROUX, G (2013). Modeling and simulation of melting curves and chemical interesterification of binary blends of vegetable oils. Chem. Eng. Sci., 87(1): 14-22. DOI: 10.1016 / j.ces.2012.09.026.

DOS SANTOS, M T; GERBAUD, V and LE ROUX, G A C (2014). Solid fat content of vegetable oils and simulation of interesterification reaction: Predictions from thermodynamic approach. J. Food Eng., 126: 198-205. DOI: 10.1016/j.jfoodeng.2013.11.012.

EBRAHIMI, L; FARMANI, J and BAHMAEI, M (2017). Description of melting curves of enzymatically interesterified blends of fully hydrogenated palm olein and soybean oil by sigmoidal functions. Food Biosci., 17(1): 29-34. DOI: 10.1016/j.fbio.2016.12.003.

FARMANI, J (2015). Modeling of solid fat content of chemically interesterified fully hydrogenated soybean oil and canola oil blends as a function of temperature and saturated fatty acids. Food Measure, 9(3): 281-289. DOI:10.1007/s11694-015-9233-8.

FARMANI, J; HAMEDI, M and SAFARI, M (2008). Production of zero trans Iranian vanaspati using chemical transesterification and blending techniques from palm olein, rapeseed and sunflower oils. Int. J. Food Sci. Technol., 43(3): 393-399. DOI: 10.1111/j.13652621.2006.01450.x.

FARMANI, J; HAMEDI, $M$; SAFARI, $M$ and MADADLOU, A (2007). Trans-free Iranian vanaspati through enzymatic and chemical transesterification of triple blends of fully hydrogenated soybean, rapeseed and sunflower oils. Food Chem., 102(3): 827-833. DOI: 10.1016/j.foodchem.2006.06.015.

FARMANI, J; SAFARI, $M$ and HAMEDI, M (2009). Trans-free fats through interesterification of canola oil/palm olein or fully hydrogenated soybean oil blends. Eur. J. Lipid Sci., 111(12): 1212-1220. DOI: 10.1002 / ejlt.200900092.

GLÄSER, K R; WENK, C and SCHEEDER, M R (2004). Evaluation of pork back fat firmness and lard consistency using several different physicochemical methods. J. Sci. Food Agric., 84(8): 853-862. DOI: 10.1002 / jsfa.1761.

KARABULUT, I; TURAN, S and ERGIN, G (2004). Effects of chemical interesterification on solid fat content and slip melting point of fat/oil blends. Eur. 
Food Res. Technol., 218(3): 224-229. DOI: 10.1007/ s00217-003-0847-4.

MAHJOOB, R; MOHAMMADI NAFCHI, A; OMIDBAKHSH AMIRI, E and FARMANI, J (2018). An investigation on the physicochemical characterization of interesterified blends of fully hydrogenated palm olein and soybean oil. Food Sci. Biotechnol., 27(2): 343-352. DOI: 10.1007/ s10068-0170262-4.

METZROTH, D J (2005). Shortenings: Science and technology. Bailey's Industrial Oil and Fat Products (Fereidoon Shahidi ed.). John Wiley \& Sons, Hoboken. p. 83-123.
NAELI, M H; FARMANI, J and ZARGARAAN, A (2017). Rheological and physicochemical modification of trans-free blends of palm stearin and soyabean oil by chemical interesterification. J. Food Process Eng., 40(2): e12409. DOI: 10.1111/jfpe.12409.

O'BRIEN, R D (2008). Fats and Oils: Formulating and Processing for Applications. CRC Press, New York.

OSPINA-E, J C; CRUZ-S, A; PEREZ-ÁLVAREZ, J A and FERNÁNDEZ-LÓPEZ, J (2010). Development of combinations of chemically modified vegetable oils as pork back fat substitutes in sausages formulation. Meat Sci., 84(3): 491-497. DOI: 10.1016/j. meatsci.2009.10.003. 